\title{
Knowledge about Systemic Arterial Hypertension in Employees of a Teaching Institution in the Metropolitan Region of Porto Alegre / RS
}

\section{Conhecimento Sobre Hipertensão Arterial Sistêmica em Colaboradores de uma Instituição de Ensino da Região Metropolitana de Porto Alegre/RS}

\author{
Paulo Ricardo Marques Filho ${ }^{\text {**; }}$ Franciely da Rosa Ferraz ${ }^{\mathrm{b}}$; Henry Güths ${ }^{\mathrm{c}}$ \\ ${ }^{a}$ Anhanguera University, Physical Therapy Course. RS, Brazil.

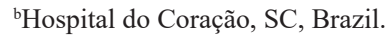 \\ 'La Salle University. RS. Brazil. \\ *E-mail:paulo.prmf1@gmail.com \\ Recebido em: 31/01/19 \\ Aprovado em: 29/07/19
}

\begin{abstract}
In occupational health actions that aimed at the clinical outcome of Hypertension (HBP) are directed in the form of informative lectures and prevalence data. The objective was to determine the level of knowledge of hypertension in employees of an educational institution in the metropolitan area of Porto Alegre / RS as a strategy for education and health promotion. Three meetings were held that consisted of evaluating the knowledge of hypertension, anthropometric data (IMC index) and physical activity level (IPAQ). Blood pressure (BP) was measured at each meeting. Statistical analysis was performed through the descriptive analysis of the variables: hypertension prevalence, blood pressure levels, level of knowledge about hypertension, mean $\pm \mathrm{SD}$, percentage. It was considered statistically significant $\mathrm{p}<0.05$. The sample consisted of 35 employees, $57.1 \%$ female and $42.9 \%$ were male. Five new hypertensive stage 1 were discovered, the classification of HBP, optimal $\mathrm{n}=$ $14(40 \%)$, normal $n=11(31.4 \%)$, borderline $n=3(8.6 \%)$, hypertension stage $1=n 7(20 \%)$. In the field "concept" most employees did not associate the term "high pressure" with hypertension disease. As for the "risk factors" and "complications" $48.6 \%$ associated with nervousness hypertension and most participants believe that HBP leads to health complications. In the treatment $28.6 \%$ know the non-pharmacological treatment. The domain "prevention" returned $100 \%$ correct when it was inquired about the prevention of hypertension. Health education programs seek to facilitate access to information about the disease, aiming at prevention, better treatment adherence and quality of life.
\end{abstract}

Keywords: Hypertension. Health Education. Occupational Health.

\section{Resumo}

Na saúde do trabalhador ações que visam o desfecho clínico de Hipertensão Arterial Sistêmica (HAS) são direcionadas na forma de palestras informativas e dados de prevalência. O objetivo foi verificar o nível de conhecimento de HAS em colaboradores de uma instituição de ensino na região metropolitana de Porto Alegre/RS como estratégia de educação e promoção em saúde. Foram realizados três encontros que consistia na avaliação do conhecimento em HAS, dados antropométricos (índice de Massa corporal) e nível de atividade física (IPAQ). A Pressão Arterial (PA) foi mensurada em cada encontro. A análise estatística foi realizada por meio da análise descritiva das variáveis: prevalência de HAS, níveis pressóricos, nível de conhecimento sobre HAS, média $\pm D P$, percentual. Foi considerado estatisticamente significativo $p<0,05$. A amostra foi composta de 35 colaboradores, 57,1\% do sexo feminino e 42,9\% do sexo masculino. Foram descobertos 5 novos hipertensos estágio 1, quanto à classificação de PA, ótima $n=14$ (40\%), normal $n=11(31,4 \%)$, limitrofe $n=3(8,6 \%)$, hipertensão estágio 1 n=7 (20\%). No domínio "conceito" grande parte dos colaboradores não associou o termo "pressão alta" a doença HAS. Quanto aos "fatores de risco" e "complicações" 48,6\% associa nervosismo a hipertensão e a maioria dos participantes acredita que a HAS leva a complicações na saúde. Já no tratamento $28,6 \%$ desconhecem o tratamento não farmacológico. O domínio "prevenção" obteve $100 \%$ de acertos quando indagamos sobre prevenção de HAS. Programas de educação em saúde buscam facilitar o acesso a informações sobre esta doença, buscando a prevenção, uma melhor adesão ao tratamento e qualidade de vida.

Palavras-chave: Hipertensão. Educação em Saúde. Saúde do Trabalhador.

\section{Introduction}

The proposals of prevention, promotion and intervention to the worker's health are aimed today at the ergonomics, and the actions that aim at the clinical outcome of chronic non-communicable diseases such as systemic arterial hypertension ( $\mathrm{SAH}$ ), are directed in the form of informative talks and prevalence data, there is a gap in the proposals of prevention, promotion and health education. The lack of labor activity presents a higher risk of developing coronary artery disease, because workers with functions related to low levels of physical activity present a greater risk when compared to workers with heavy and/or active functions, evidencing the physical activity as a protective factor against cardiovascular diseases ${ }^{1}$.

At the beginning of the century non-transmissible chronic diseases were more frequent in higher-income classes, where today there was a reversal of this framework and began to affect the population groups of lower income, lower level of schooling and worse living conditions ${ }^{2}$. SAH is one of the main chronic non-communicable diseases (CNCD), being a major risk factor for cardiovascular diseases ${ }^{3}$. 
SAH can be diagnosed when the blood pressure levels, in most measurements are above levels considered normal, then it is associated to a factor of development of cardiovascular involvement if not treated. Its characterization occurs with the elevation of systolic levels above $140 \mathrm{Mmhg}$ and diastolic pressure above $90 \mathrm{mmhg}^{4}$. Hypertensive individuals have a greater risk of developing diabetes mellitus (DM) taking into account the same harmful habits, thus there is a heightened risk of developing cardiovascular problems throughout $\operatorname{life}^{5}$, and therefore there is importance in counseling of these individuals through education about their disease to changes in dietary habits, physical activity, treatment and current condition ${ }^{6.7}$. The patients' adherence to the guidelines for control of signs and symptoms of diseases is related to the superficial form that is passed by health professionals by means of lectures and bulletins. Thus, it is ensured that the work with groups provides a further deepening of discussions by which could expand knowledge and better leads the process of education in health, where people can overcome their difficulties obtaining greater autonomy in their health condition ${ }^{8}$.

The patients' level of knowledge is of paramount importance, because it allows the understanding of the factors of their disease and contributes to a more active collaboration of the patients, guiding their action for health promotion and disease prevention. In the educative actions in groups the improvement of knowledge of hypertensive individuals and the community has been suggested, having as main objective to improve adherence, involving the patient and family in the dynamics of their own control allowing them to consciously choose for better life habits ${ }^{9}$.

It is estimated that $\mathrm{SAH}$ presents the global prevalence average around $26.4 \%$, in Brazil is around $24.8 \%$ without distinction of gender ${ }^{10}$. These diseases are considered as public health problems of difficult diagnosis and control, there is the need to obtain the population knowledge of these diseases for which can be quantified, and from this to propose strategies for prevention, promotion and health education ${ }^{11}$.

Thus, the general objective of this study is to determine the level of knowledge on hypertension in employees of an education institution in the metropolitan region of Porto Alegre/RS.

\section{Materials and Methods}

\subsection{Study Design}

The present study is cross-sectional quantitative, i.e., the data were collected in a single moment without intervention.

After the approval of the project by the Committee of Ethics and Research according to the opinion 0065.0.404.000-11 the steps for selecting the samples began. The researcher was directed to sectors of the IHES, where he made the invitation to collaborators, after they met the criteria for inclusion in the study and signing the Informed Consent Form (ICF) the data collections were initiated.
As inclusion criteria the subjects should be employees of the institution of education, more than 18 years and sign the informed consent form.

Among the exclusion criteria were employees who participate or have participated formally of some activities of education or health promotion in hypertension, taking into consideration that the prior knowledge on the subject will directly influence in the study, because the general objective of the study is to assess the level of knowledge about SAH.

The population was composed of 500 employees, and 210 professors and 290 from other sectors, the calculation initially included 210 employees, however, due to the period of the study, a sample of 35 employees was covered of an education institution in the metropolitan region of Porto Alegre aged between 19 and 73 years old of both sexes who agreed to sign the Informed Consent Form, according to the resolution $466 / 12$ of the National Health Council that regulates research involving human beings.

All the collections were carried out at the place of work on a scheduled time with the corresponding sector of the institution of higher education. The evaluation was performed in three meetings. At the first meeting the application of a questionnaire was carried out of the collaborator's profile, followed by the questionnaire for the evaluation of the level of knowledge on hypertension and after measurement of blood pressure (sphygmomanometer brand Durashock model DS44-BR and a stethoscope BIC standard adult ESO128 model). In the second meeting the anthropometric data were evaluated such as weight, height, BMI, waist circumference (anthropometric scale Ramuza brand DP model 200 and metric tape SECA brand), application of IPAQ, questionnaire which evaluates the level of physical activity ${ }^{12}$ and measurement of blood pressure. In the third meeting there was only the measurement of blood pressure. All the collaborators who agreed to participate in the project performed all the steps of the study, regardless of previous diagnosis of SAH or anthropometric measures.

\subsection{Statistical analysis}

The statistical analysis was performed using SPSS version 18. Statistical analysis was performed through the descriptive analysis of the variables: SAH prevalence, blood pressure levels, level of knowledge about hypertension, mean $\pm \mathrm{SD}$, percentage. It was considered statistically significant $\mathrm{p}<0.05$.

\section{Results and Discussion}

The sample was composed of $57.1 \%$ of female participants $(n=20)$ and $42.9 \%$ of males $(n=15)$, with a mean age of 34.89 \pm 11.86 being minimum age of 19 years and maximum age of 73 years (Table 1). Supplies sector $5.71 \%(n=2)$, informatics $11.43 \%(\mathrm{n}=4)$, sanitizing $11.43 \%(\mathrm{n}=4)$, surveillance, $22.86 \%$ $(n=8)$, teaching $20 \%(n=7)$, marketing, $28.57 \%(n=10)$. 
Table 1 - Characteristics of the sample.

\begin{tabular}{|c|c|c|c|}
\hline Characteristics & $\mathbf{n}(35)$ & Mean \pm SD & $\%$ \\
\hline \multicolumn{4}{|l|}{ Sex } \\
\hline Female & & 20 & 57.1 \\
\hline Male & & 15 & 42.9 \\
\hline Age $($ mean $\pm \mathrm{SD}){ }^{*}$ & 34.89 & \pm 11.68 & \\
\hline \multicolumn{4}{|l|}{ Associated pathologies } \\
\hline Diabetes & & 1 & 2.9 \\
\hline Heart disease & & 1 & 2.9 \\
\hline Others & & 1 & 2.9 \\
\hline \multicolumn{4}{|l|}{ Medicines } \\
\hline Atenolol & & 3 & 8.6 \\
\hline Others & & 3 & 8.6 \\
\hline \multicolumn{4}{|l|}{ Schooling } \\
\hline Elementary school incomplete & & 6 & 17.1 \\
\hline Elementary school complete & & 2 & 5.7 \\
\hline High school incomplete & & 2 & 5.7 \\
\hline High school complete & & 1 & 2.9 \\
\hline Higher Education Incomplete & & 10 & 28.6 \\
\hline Higher Education Complete & & 14 & 40.0 \\
\hline \multicolumn{4}{|l|}{$\begin{array}{l}\text { Family income (minimum } \\
\text { wage) }\end{array}$} \\
\hline Up to one minimum wage & & 5 & 14.3 \\
\hline Up to two minimum wages & & 6 & 17.1 \\
\hline Up to three minimum wages & & 1 & 2.9 \\
\hline More than four minimum wages & & 23 & 65.7 \\
\hline
\end{tabular}

Values expressed in mean \pm and standard deviation.

Source: Research Data.

Regarding the analysis of associated pathologies, the collaborators had prior diagnosis of: diabetes $2.9 \%(\mathrm{n}=1)$, heart disease, $2.9 \% \quad(n=1)$ and with other pathologies $2.9 \%(\mathrm{n}=1)$, the drugs atenolol corresponded to $8.6 \%(\mathrm{n}=3)$ and other medicines $8.6 \%(\mathrm{n}=3)$. In relation to schooling elementary school incomplete, $17.1 \%(n=6)$, the elementary school complete $5.7 \%(\mathrm{n}=2)$, high school incomplete, $5.7 \%$ $(n=2)$, high school complete $2.9 \%(n=1)$, upper education incomplete $28.6 \%(\mathrm{n}=10)$, upper education complete $40.0 \%$ $(n=14)$. The family income, $14.3 \%$ of the participants reported having a monthly income of up to one minimum wage $(n=5)$, with monthly income of two minimum wages, $17.1 \%(n=6)$, up to three minimum wages $2.9 \%(\mathrm{n}=1)$ and with more than four minimum wages, $65.7 \%(\mathrm{n}=23)$ (Table 1).

The anthropometric data were expressed as mean and standard deviation, the weight of the collaborators was on average $75.10 \pm 15.7$, the height was $1.7 \pm 0.98$, the mean BMI was stratified by sex where it was obtained the average of $24.82 \pm 3.26$ females and average of $27.17 \pm 5.13$ males, the abdominal circumference was also stratified by sex, $77.9 \pm$ 7.76 females and an average of $89.33 \pm 12.96$ males (Table 2).
Table 2 - Anthropometric data.

\begin{tabular}{|l|c|c|c|}
\hline $\begin{array}{l}\text { Anthropometric } \\
\text { data }\end{array}$ & Maximum & Minimum & Mean \pm SD \\
\hline $\begin{array}{l}\text { Weight }(\mathrm{Kg}, \\
\text { mean } \pm \mathrm{SD})\end{array}$ & 131.2 & 54.0 & $75.10 \pm 15.7$ \\
\hline $\begin{array}{l}\text { Height }(\mathrm{m}, \text { mean } \\
\pm \mathrm{SD})\end{array}$ & 2.00 & 1.52 & $1.7 \pm 0.98$ \\
\hline $\begin{array}{l}\text { BMI }\left(\mathrm{Kg} / \mathrm{m}^{2},\right. \\
\text { mean } \pm \mathrm{SD})\end{array}$ & $\begin{array}{c}32.4(\mathrm{f}) \\
41.9(\mathrm{~m})\end{array}$ & $\begin{array}{c}19.9(\mathrm{f}) \\
21.6(\mathrm{~m})\end{array}$ & $\begin{array}{c}24.82 \pm 3.26(\mathrm{f}) \\
27.17 \pm 5.23(\mathrm{~m})\end{array}$ \\
\hline $\begin{array}{l}\text { Abdominal } \\
\text { circumference } \\
\text { (cm, mean } \pm \mathrm{SD})\end{array}$ & $\begin{array}{c}90(\mathrm{f}) \\
122(\mathrm{~m})\end{array}$ & $\begin{array}{c}65(\mathrm{f}) \\
75(\mathrm{~m})\end{array}$ & $\begin{array}{c}77.95 \pm 7.76(\mathrm{f}) \\
89.33 \pm 12.96\end{array}$ \\
\hline
\end{tabular}

The variables were expressed as mean \pm standard deviation. Female $(n=20)$, male $(n=15)$.

Source: Research Data.

Of the total surveyed $5.7 \%$ of the collaborators reported to be hypertensive $(n=2)$ when evaluated the mean blood pressure it was observed systolic blood pressure of 123.29 \pm 13.12 and mean diastolic blood pressure of $74.67 \pm 10.17$ (Table 3), the classification of blood pressure it was found optimal PA $40 \%(\mathrm{n}=14)$, normal $31.4 \%(\mathrm{n}=11)$, borderline $8.6 \%(\mathrm{n}=3)$, stage 1 hypertension $20 \%(\mathrm{n}=7)$ (Figure 1$)$.

Table 3 - Data of blood pressure.

\begin{tabular}{|l|c|c|c|}
\hline & $\mathbf{n}=\mathbf{3 5}$ & $\begin{array}{c}\text { Mean } \pm \\
\text { SD }\end{array}$ & \% \\
\hline Prior diagnosis of hypertension & 2 & & 5.7 \\
\hline Without diagnosis & 33 & & 94.3 \\
\hline Blood pressure (mean \pm SD) & & & \\
\hline Systolic pressure (mmHg) & & $\begin{array}{c}123.29 \pm \\
13.12\end{array}$ & \\
\hline Diastolic pressure (mmHg) & & $\begin{array}{c}74.67 \pm \\
10.17\end{array}$ & \\
\hline
\end{tabular}

The variables of systolic pressure and diastolic pressure were expressed as mean $\pm \mathrm{SD}$. Three measures were taken of BP (VI Brazilian Hypertension Guidelines).

Source: Research Data.

Figure 1 - Analysis of the classification of blood pressure based on three measurements of BP (VI Brazilian Hypertension Guidelines). Optimal $(\mathrm{n}=14)$, normal $(\mathrm{n}=11)$, pre-hypertensive patients $(n=3)$ and stage 1 hypertension $(n=7)$

\section{Classificação da pressão arterial}

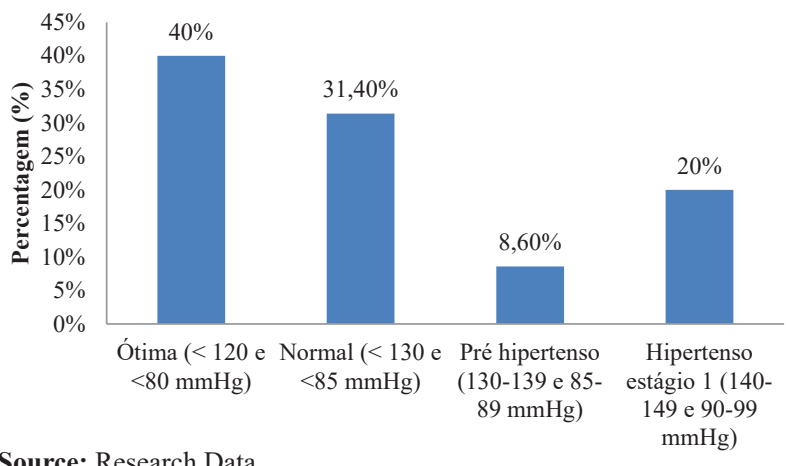

Source: Research Data.

In relation to the level of physical active females $35 \%$ were characterized as active $(\mathrm{n}=7), 40 \%$ irregularly active $(\mathrm{n}=8)$, irregularly active B $20 \%(\mathrm{n}=4)$ and sedentary $5 \%$ 
$(\mathrm{n}=1)$, males $26.7 \%$ active $(\mathrm{n}=4)$, irregularly active, $26.7 \%$ $(\mathrm{n}=4)$ and irregularly active B $46.7 \%(\mathrm{n}=7)$ none of the male participants were classified as sedentary.

The percentage of "hits", "errors" and "I don't know" of the questionnaire which evaluates the level of knowledge about hypertension is shown in Table 5.
Table 4 - Level of physical activity.

\begin{tabular}{|l|c|c|c|c|}
\hline IPAQ classification & $\mathbf{n = 3 5}$ & & \% & \\
\hline Active & $7(\mathrm{f})$ & $4(\mathrm{~m})$ & $35(\mathrm{f})$ & $26.7(\mathrm{~m})$ \\
\hline Irregularly active & 8 & $4(\mathrm{~m})$ & $40(\mathrm{f})$ & $26.7(\mathrm{~m})$ \\
\hline Regularly active $\mathbf{B}$ & 4 & 7 & $20(\mathrm{f})$ & $46.7(\mathrm{~m})$ \\
\hline Sedentary & 1 & 0 & $5(\mathrm{f})$ & $0(\mathrm{~m})$ \\
\hline
\end{tabular}

Source: Research Data.

Table 5 - Percentage of hits, errors and I don't know.

\begin{tabular}{|c|c|c|c|c|c|c|}
\hline & \multicolumn{2}{|c|}{ Hit } & \multicolumn{2}{|c|}{ Error } & \multicolumn{2}{|c|}{ I don't know } \\
\hline & $\mathrm{N}$ & $\%$ & $\mathrm{~N}$ & $\%$ & $\mathrm{~N}$ & $\%$ \\
\hline \multicolumn{7}{|l|}{ Domain "concept" } \\
\hline 1 High blood pressure is considered a disease. & 33 & 94.3 & 2 & 5.7 & 0 & 0 \\
\hline 2 Hypertension and high blood pressure is not the same thing. & 19 & 54.3 & 9 & 25.7 & 7 & 20 \\
\hline 3 High pressure may not present symptoms. & 19 & 54.3 & 10 & 28.6 & 6 & 17.1 \\
\hline 4 We can say that 12 per 8 is considered high blood pressure. & 26 & 74.3 & 1 & 2.9 & 8 & 22.9 \\
\hline 5 Pressure is related to the socioeconomic condition. & 26 & 74.3 & 3 & 8.3 & 6 & 17.1 \\
\hline \multicolumn{7}{|l|}{ Domain "risk factors" } \\
\hline 6 Nervous people have high blood pressure. & 18 & 51.4 & 11 & 31.4 & 6 & 17.1 \\
\hline 7 Obese people may develop high blood pressure. & 31 & 88.6 & 0 & 0 & 4 & 11.4 \\
\hline 8 The habit has no relation with high pressure. & 25 & 71.4 & 3 & 8.6 & 7 & 20 \\
\hline 9 Drinking alcohol in excess causes an increase in pressure. & 22 & 62.9 & 5 & 14.3 & 8 & 22.9 \\
\hline 10 If your father or your mother has high blood pressure, you may also have. & 21 & 60 & 4 & 11.4 & 10 & 28.6 \\
\hline \multicolumn{7}{|l|}{ Domain "complications" } \\
\hline 11 Having high blood pressure does not bring complications to your health. & 31 & 88.6 & 2 & 5.7 & 2 & 5.7 \\
\hline 12 Having high blood pressure and not treating do not compromise your health. & 34 & 97.1 & 1 & 2.9 & 0 & 0 \\
\hline 13 High pressure brings problems to your heart and kidneys. & 26 & 74.3 & 2 & 5.7 & 7 & 20 \\
\hline 14 People who have high blood pressure are at risk of stroke. & 31 & 88.6 & 4 & 11.4 & 0 & 0 \\
\hline 15 High blood pressure is not associated with other diseases. & 24 & 68.6 & 4 & 11.4 & 7 & 20 \\
\hline \multicolumn{7}{|l|}{ Domain "treatment" } \\
\hline 16 The treatment of high blood pressure is for the whole life & 25 & 71.4 & 5 & 14.3 & 5 & 14.3 \\
\hline 17 High blood pressure is treated only with the use of medicines. & 25 & 71.4 & 6 & 17.1 & 4 & 11.4 \\
\hline 18 The control of blood pressure should be done regularly. & 30 & 85.7 & 0 & 0 & 5 & 14.3 \\
\hline 19 If the pressure is controlled I can stop taking the medicine. & 27 & 77.1 & 1 & 2.9 & 7 & 20 \\
\hline 20 The medicines for high blood pressure should be taken in the times established & 32 & 91.4 & 0 & 0 & 3 & 8.6 \\
\hline \multicolumn{7}{|l|}{ Domain "prevention" } \\
\hline 21 Doing physical exercise has no relation with the control of blood pressure. & 31 & 88.6 & 0 & 0 & 4 & 11.4 \\
\hline 22 Weight control assists the control of blood pressure. & 31 & 88.6 & 3 & 8.6 & 1 & 2.9 \\
\hline 23 Reducing salt in the food controls blood pressure. & 31 & 88.6 & 1 & 2.9 & 3 & 8.6 \\
\hline 24 High pressure can be avoided & 26 & 74.3 & 0 & 0 & 9 & 25.7 \\
\hline 25 Having knowledge about what high blood pressure is, helps to prevent it. & 35 & 100 & 0 & 0 & 0 & 0 \\
\hline
\end{tabular}
Source: Research Data.

The level of knowledge on Hypertension, prevalence of disease are aspects related to primary health care, since this pathology has asymptomatic characteristics making difficult the diagnosis. In this study 5 new patients classified as hypertension stage 1 and 3 as pre-hypertensive were discovered, $20 \%$ being classified as hypertensive and $8.6 \%$ pre-hypertensive, these data are in agreement with the literature, where the prevalence of hypertensive patients in the Brazilian population is $22.3 \%$ without distinction of sex. The level of knowledge in the domain "concept", a large part of the collaborators do not understand the meaning of SAH, and they are also unaware of the asymptomatic phase of the disease.

In the classification of blood pressure three collaborators were discovered as pre-hypertensive and five hypertensive patients in stage 1. Studies point the pre-hypertension as a precursor of hypertension. The observation of the behavior of BP for 50 years, in 5,181 participants in the study of Farminghan, revealed that individuals classified as prehypertensive patients progressed to the stage of hypertension with greater frequency than normotensive individuals ${ }^{13}$. On the other hand, it was observed that these participants were irregularly active. These data confirm what has been shown in the literature on the effects of the lack of physical activity 
in SAH. The prevention of SAH and the control of blood pressure in hypertensive patients are necessary measures for the reduction of cardiovascular morbidity and mortality. The changes in lifestyle are one of the most important tools for effective reduction of blood pressure. Most studies demonstrate that implementation of regular physical activity reduces the risk of normotensive individuals to develop hypertension and is associated with a significant reduction in systolic and diastolic blood pressure ${ }^{14}$.

In the domain "concept" most collaborators did not associate the term "high pressure" to SAH disease. A study with hypertensive patients from the public health network in the city of São Paulo with the objective of knowing attitudes, beliefs, perceptions, thoughts and practices of these patients, observed that $38 \%$ of the patients did not define what hypertension is and $41 \%$ of the subjects associated the concept of SAH to high blood pressure, claiming to be the same thing. While nearly half of the sample did not define what high blood pressure is, the results indicate a lack of concepts of hypertension on the part of the collaborators. Although a large proportion of them should have received some kind of orientation of health professionals, they assume that these newsletters were not effectively absorbed or understood ${ }^{15}$.

The participants were unaware of the asymptomatic phase of SAH, since $45.7 \%$ erred or did not know how to answer this question. SAH can evolve in an asymptomatic manner, and the most common symptoms match easily with other diseases confusing the patients. Its diagnosis depends, therefore, that the patient try to measure his or her blood pressure spontaneously or make periodic examinations, since in some cases it will be diagnosed late when the patient already has complications $^{16}$.

In the domain "risk factors" when asked about the relationship of SAH to nervousness, almost half of the participants did not hit, because it was obtained $48.6 \%$ of error. Most of the population associates the nervousness to the development of SAH, because individuals exposed to stress factors even acutely can develop hypertensive crisis that is the result of an abrupt elevation of arterial pressure, in which very high blood pressure levels are observed, accompanied by signs and symptoms, such as severe headache, feeling of unease, anxiety, restlessness, dizziness, chest pain, dyspnea, visual disorders and vasospasms upon the examination of the eye function. It may occur in individuals with blood pressure usually within ranges of normality, in individuals with hypertension even without a definite diagnosis and in patients with hypertension diagnosed and in treatment, and, in these cases, often due to non-adherence of the therapeutic regimen ${ }^{17}$.

In the domain "complications", statements like "Having high blood pressure, and not treating affect your health", there was a high percentage of hits among the collaborators, in contrast in the statement "high blood pressure is not associated with other diseases" $31.4 \%$ believed that hypertension is not a risk factor for the development of other comorbidities. The most known complications about hypertensive disease are stroke and acute myocardial infarction, few people recognize other involvements which seems to indicate a partial knowledge about the complications of hypertension ${ }^{18}$.

As the domain "treatment" $28.6 \%$ of the participants were unaware of the non-pharmacological treatment of hypertension. There was a very high level of knowledge to aspects relating to food, excess weight, habits such as smoking, alcohol and stress of daily life ${ }^{19}$. It is believed that the hypertensive population should know all aspects inherent to the disease and its treatment. One must be warned about the different forms of SAH control and the importance of its continuity, making it effective. It is considered the educational process as unquestionable factor for the appropriate follow-up of treatment. Only guidelines to the hypertensive population about the disease and treatment does not imply an effective follow-up of the proposed conducts, because behavioral changes are often required.

Physical exercises even in moderate degrees, has a protective effect against coronary disease and on all causes of mortality and a series of other benefits: elevation of HDLcholesterol, reduction of blood pressure levels and assists in reducing body weight ${ }^{20}$.

The domain "prevention" $25.7 \%$ are unaware of ways to prevent the development of SAH. The scientific evidences of preventive measures in delaying the onset of non-transmissible chronic diseases are becoming increasingly frequent, however programs which emphasize the primary health attention are still scarce. The importance of knowledge about preventive measures to $\mathrm{SAH}$ is one of the possible paths for the adoption of a more active lifestyle in order to promote quality of life, increase in health conditions and reduction of public spending with the palliative treatment of these diseases ${ }^{21}$.

\section{Conclusion}

From the data surveyed gaps were found in knowledge about hypertension, making it necessary to deploy a health education program to provide easier access to information about this disease, seeking the prevention, treatment adherence and improvement in the quality of life of the collaborators.

\section{References}

1. Bethany BG, Kelley PG, Jared PR, John MJ, Mercedes RC, Barbara S. Cross-sectional and longitudinal associations between objectively measured sedentary time and metabolic disease: the Coronary Artery Risk Development in Young Adults (CARDIA) Study. Diabetes Care 2015;38(10):183543. doi: $10.2337 / \mathrm{dc} 15-0226$.

2. Davide R, Michael OH, Marina LP, Rosana A, Mauricio LB. Impact of primary health care on mortality from heart and cerebrovascular diseases in Brazil: a nationwide analysis of longitudinal data. BMJ 2014;349:g4014. doi: 10.1136/bmj. 
g4014

3. David AC, John NB, Suzanne O, Marguerite RI, Daichi SS, Daniel TL, et. al. Determination of prevalence, risk factors, and comorbidities in a large, population-based cohort. Hypertension 2014;63:451-8. doi: 10.1161/ HYPERTENSIONAHA.113.02026

4. Robert M. Carey, MD; Paul KW. Prevention, Detection, Evaluation, and Management of High Blood Pressure in Adults: Synopsis of the 2017 American College of Cardiology/American Heart Association Hypertension Guideline. ACC/AHA Hypertension Guideline Writing Committee. Ann Intern Med 2018;168(5):351-8. doi: 10.7326/M17-3203

5. Jacobs AK, Anderson JL, Halperin JL, Anderson JL, Halperin JL, Albert NM. et al. ACC/AHA Task Force Members. The evolution and future of ACC/AHA clinical practice guidelines: a 30-year journey: a report of the American College of Cardiology/American Heart Association Task Force on Practice Guidelines. Circulation. 2014;64(3):120817. doi: 10.1016/j.jacc.2014.06.001

6. Thomopolous C, Parati G, Zanchetti A. Effects of blood pressure lowering on outcome incidence in hypertension: Effects of more vs less intensive blood pressure lowering and different achieved blood pressure levels: updated overview and meta-analysis of randomized trials. J Hypertens 2016;34(4):613-22. doi: 10.1097/ НJH.0000000000000881.

7. Xie X, Atkins EL, Bennett A, Neal B, Ninomiya $T$, et al. Effects of intensive blood pressure lowering on cardiovascular and renal outcomes: updated systematic review and meta-analysis. Lancet 2016;387(10017):435-43. doi: 10,1016/S0140-6736(15)00805-3

8. Mario S, Jose L, Shakir C, Ammar A, Clio O, John CM. Effects of the Dietary Approach to Stop Hypertension (DASH) diet on cardiovascular risk factors: a systematic review and meta-analysis. British J Nutr 2015;113:1-15. doi: 10.1017/S0007114514003341

9. Helena LQ, Paul AL, Dina B, Pablo P, Patricio LJ, Robby N, et. al. Patients' knowledge, attitudes, behaviour and health care experiences on the prevention, detection, management and control of hypertension in Colombia: a qualitative study. PLoS One 2015;10(4):e0122112. doi: 10.1371/journal. pone.0122112.

10. Lanas F, Avezum A, Bautista L, Diaz R, Luna M, Islam S. Risk factors for acute myocardial infarction in Latin America: the INTERHEART Latin American study. Circulation 2007;115(9):1067-74. doi: 10.1161/ CIRCULATIONAHA.106.633552

11. Khatib R, Schwalm JD, Yusuf S, Haynes RB, McKee M,
Khan M, et al. Patient and healthcare provider barriers to hypertension awareness, treatment and follow up: a systematic review and meta-analysis of qualitative and quantitative studies. PLoS One. 2014. doi: 10.1371/journal. pone. 0084238 .

12. Giovana ZP, Tânia BB. Adaptation of the international physical activity questionarie for the elderly. Rev Bras Cineantropom Desempenho Hum 2010;12(6):480-4. doi: 10.5007/1980-0037.2010v12n6p480

13. Stella SD, Doreen MR, Kelly BZ, Kaberi D, Kara N, et. al. The 2015 Canadian hypertension education program recommendations for blood pressure measurement, diagnosis, assessment of risk, prevention, and treatment of hypertension. Can J Cardiol 2015;31(5):549-68. doi: 10.1016/j.cjca.2015.02.016.

14. Victor CN, Sandro SL, Aureliano IS, Geraldo MN, Alexandre P. Arterial hypertension among adolescents in Rio de Janeiro: prevalence and association with physical activity and obesity. Ciênc Saúde Coletiva 2014;19(6):1699708. doi: 10.1590/1413-81232014196.05262013

15. Deborah CM, Regina TB, Silvânia AS, Marta MS, Gustavo VM. Rev Saúde Pública 2017. doi: 10.1590/s15188787.2017051000006

16. Gustavo BO, Alvaro A, Leonardo R. Cardiovascular disease burden: evolving knowledge of risk factors in myocardial infarction and stroke through population-based research and perspectives in global prevention. Front Cardiovasc Med 2015;13(2):32. doi: 10.3389/fcvm.2015.00032.

17. Paulo AL, Alexandre CP, Paulo SV, Itamar SS, Jose GM, Isabela MB. Resistant hypertension: risk factors, subclinical atherosclerosis, and comorbidities among adults - The Brazilian Longitudinal Study of Adult Health (ELSA $\square$ Brasil). J Clin Hypertens (Greenwich) 2015;17(1):74-80. doi: $10.1111 /$ jch. 12433 .

18. Liana CG, Shadi K, Fumiaki I, Rozenn L, David SS, Bruce MP, Dariush M. Contribution of major lifestyle risk factors for incident heart failure in older adults. JACC Heart Fail 2015;3(7):520-8. doi: 10.1016/j.jchf.2015.02.009.

19. Irene AK, Frances TD, Samuel AD. Mental health in hypertension: assessing symptoms of anxiety, depression and stress on anti-hypertensive medication adherence. Int $\mathbf{J}$ Ment Health Syst 2014;8:25. doi: 10.1186/1752-4458-8-25

20. Mulvany MJ. Small Artery Remodeling and Significance in the development of hypertension. Am J Physiol 2018;17(3). doi: 10.1152/nips.01366.2001.

21. Connor AE, Simon GA, Mark W, Kazem R. Usual Blood Pressure and risk of new-onset diabetes. J Am Coll Cardiol 2016;66(14):1552-62. doi: 10.1016/j.jacc.2015.07.059 